\title{
Isolation of Lactic Acid Bacteria from Idli Batter and Screening of Characters as Potential Starter Cultures for Development of Functional Food Using Bacopa monnieri ${ }^{\dagger}$
}

\author{
Elizabeth P. Thomas ${ }^{1, *}$, Maria Thomas ${ }^{1}$, Mary Magthilin ${ }^{1}$, Mereena Jose ${ }^{1}$, Mrudula Babu ${ }^{1}$ \\ 1 Department of Microbiology, St. Mary's College, Thrissur, Kerala, India \\ * Correspondence: eptkiran@gmail.com; \\ $\dagger$ Presented at International e-Conference on Bioengineering for Health and Environment (ICBHE 2020)
}

Received: 5.07.2020; Revised: 10.07.2020; Accepted: 12.07.2020; Published: 15.07.2020

\begin{abstract}
Functional foods are whole, fortified, enriched, or enhanced foods that provide health benefits to humans regularly. Numerous plant foods or physiologically active ingredients derived from plants have been investigated for their role in disease prevention and health. Natural lactic acid fermentation of Idli batter by lactic acid bacteria and yeast makes Indian breakfast as a potential source of probiotic microorganisms. Briefly, the organism was isolated; the predominant isolate was considered on the basis of colony morphology, staining techniques, and biochemical tests. Growth conditions of the organism, such as $\mathrm{pH}$, salt tolerance, bile salt tolerance, heat sensitivity, were studied. Bacopa monnieri (Brahmi juice) was extracted and fermented with predominant isolate as a starter culture. Organoleptic, antioxidant, and antibacterial properties of the fermented product were evaluated. On staining, the predominant isolate was identified as Gram-positive non-spore-forming, non-motile rod shape bacteria. The phenotypic characteristics were further resolved on the basis of growth patterns in $\mathrm{pH}$, salt, bile salt, and heat sensitivity. In conclusion, the study of biological efficacies of fermented extracts of Bacopa monnieri reveals the potent activities in the field of science.
\end{abstract}

Keywords: Functional food; Lactic acid bacteria; Starter culture.

(C) 2020 by the authors. This article is an open-access article distributed under the terms and conditions of the Creative Commons Attribution (CC BY) license (https://creativecommons.org/licenses/by/4.0/).

\section{Funding}

This research received no external funding.

\section{Acknowledgments}

This research has no acknowledgment.

\section{Conflicts of Interest}

The authors declare no conflict of interest. 